\title{
New developments in the treatment of optic neuritis
}

\author{
This article was published in the following Dove Press journal: \\ Eye and Brain \\ 17 June 2010 \\ Number of times this article has been viewed
}

\author{
Thomas M Jenkins' \\ Ahmed T Toosy ${ }^{2}$ \\ 'Department of Neurology, Royal \\ Hallamshire Hospital, Sheffield, \\ UK; ${ }^{2}$ Department of Brain Repair \\ and Rehabilitation, UCL Institute \\ of Neurology, University College \\ London, London, UK
}

Correspondence: T M Jenkins Department of Neurology, Royal Hallamshire Hospital, Sheffield, SIO 2PN, UK

$\mathrm{Tel}+44 \mid$ I 427 I 1900

Email t.jenkins@ion.ucl.ac.uk
Abstract: Acute optic neuritis $(\mathrm{ON})$ has various etiologies. The most common presentation is inflammatory, demyelinating, idiopathic, or "typical" ON, which may be associated with multiple sclerosis. This must be differentiated from "atypical" causes of $\mathrm{ON}$, which differ in their clinical presentation, natural history, management, and prognosis. Clinical "red flags" for an atypical cause of ON include absent or persistent pain, exudates and hemorrhages on fundoscopy, very severe, bilateral, or progressive visual loss, and failure to recover. In typical ON, steroids shorten the duration of the attack, but do not influence visual outcome. This is in contrast to atypical ON associated with conditions such as sarcoidosis and neuromyelitis optica, which require aggressive immunosuppression and sometimes plasma exchange. The visual prognosis of typical ON is generally good. The prognosis in atypical $\mathrm{ON}$ is more variable. New developments aimed at designing better treatments for patients who fail to recover are discussed, focusing on recent research elucidating mechanisms of damage and recovery in ON. Future therapeutic directions may include enhancing repair processes, such as remyelination or adaptive neuroplasticity, or alternative methods of immunomodulation. Pilot studies investigating the safety and proof-ofprinciple of stem cell treatment are currently underway.

Keywords: optic neuritis, multiple sclerosis, neuromyelitis optica, steroids, neuroplasticity, stem cells

Optic neuritis $(\mathrm{ON})$ is defined as inflammation of the optic nerve. This general definition describes a common pathological phenotype, which may be caused by a wide range of heterogeneous conditions, varying greatly in their clinical features, natural history, treatment, and prognosis. The most commonly encountered syndrome is acute, inflammatory, demyelinating ON that may be associated with multiple sclerosis (MS). This will be referred to as typical $\mathrm{ON}$ in this review. Patients with typical ON generally make a good visual recovery and, although steroids are sometimes used to reduce the duration of the clinical attack, the overall visual recovery is unaffected by treatment. This is in contrast to some of the other, atypical, inflammatory, and infective causes of ON, in which the visual prognosis may be poor if left untreated. These types of ON differ in their clinical features from typical $\mathrm{ON}$, and will be referred to collectively as atypical $\mathrm{ON}$ in this review. Atypical ON may be associated with non-MS inflammatory diseases of the central nervous system (CNS). In these patients, visual recovery is dependent on prompt immunosuppressive treatment, and delays in diagnosis can have serious consequences. Therefore, it is critical that these steroid-responsive, atypical optic neuritides are distinguished from typical ON, in order to select the group of patients who will benefit from immunosuppression. 
A minority of patients with typical $\mathrm{ON}$ fail to recover. At present, there are no effective treatments for these people. Recent research has elucidated the reasons underlying the mechanisms of damage and visual recovery in $\mathrm{ON}$, which may lead to better therapies in the future.

In this review, we will outline the principles of diagnosis and management of ON. We will discuss the epidemiology, etiology, and common clinical presentation of typical ON. We will then discuss differential diagnosis, and emphasize the importance of identifying clinical "red flags" to help distinguish atypical ON. We will describe the differences in natural history, treatment, and prognosis of these two syndromes. Recent progress into understanding the pathophysiology of typical ON will then be reviewed, with a focus on future treatment directions for patients who fail to make a good visual recovery.

\section{Epidemiology and etiology}

The prevalence and incidence of $\mathrm{ON}$ varies across the world. Typical ON becomes more common with increasing latitude, in a similar manner to MS. A study based in the UK reported a lifetime prevalence of 0.6 per 1000 and an age and sex adjusted incidence of 1 per 100,000 per year. ${ }^{1}$ A similar study based in the USA reported an age and sexadjusted prevalence of 115 per 100,000 and an incidence rate of 5 per 100,000 per year. $^{2}$ In Sweden researchers reported rather lower age-adjusted overall incidence rates of 1.40 per 100,000 per year $(2.28$ per 100,000 for females and 0.53 per 100,000 for males). ${ }^{3}$ This was somewhat surprising, given the high latitude of Scandinavia, but rates were still much higher than for people born outside of Nordic countries, for whom the rate was 0.28 per 100,000 per year. $^{3}$ There is a seasonal pattern to the incidence, with rates highest in the spring. ${ }^{4}$

Typical ON most commonly affects young Caucasian women in their late 20 s and early 30 s. The mean age of onset is 31 to 32 years, ${ }^{5,6}$ although it is well recognized both in children and the elderly. The female to male ratio is approximately $3: 1 .^{5}$ Atypical optic neuritides are more variable in terms of demographics. Some types of atypical ON are more common in different ethnic groups, for example, sarcoidosis is more common in black people.

The cause of typical ON is unknown. As it is often associated with MS, it is thought that the two conditions share a common etiology. There are probably complex interactions between genetic predisposition and environmental triggers, that have yet to be identified but may include infectious agents and vitamin D deficiency. ${ }^{7,8}$ Atypical ON may be caused by infections, or be related to other inflammatory and autoimmune diseases (Table 1).

Table I Causes of atypical optic neuritis

\begin{tabular}{|c|c|c|}
\hline Etiology & Cause of ON & Clinical clues \\
\hline \multirow[t]{9}{*}{ INFLAMMATORY } & Neuromyelitis optica & $\begin{array}{l}\text { Longitudinally extensive myelitis, positive anti-aquaporin- } 4 \text { antibodies, } \\
\text { CSF cells but negative OCBs }\end{array}$ \\
\hline & Sarcoidosis & $\begin{array}{l}\text { Respiratory involvement, hilar lymphadenopathy, sometimes } \\
\text { neuroretinitis, vitritis, uveitis (although uveitis may be seen in typical ON } \\
\text { too }{ }^{29} \text { ), meningeal enhancement on MRI, CSF cells }\end{array}$ \\
\hline & SLE & Rash, arthritis, multiorgan involvement, positive ANA, and dsDNA, CSF cells \\
\hline & Behçet's & Mouth and genital ulcers, CSF cells, positive skin pathergy test \\
\hline & Chronic relapsing & Relapses off steroids, no other inflammatory cause found, normal brain \\
\hline & inflammatory optic & MRI, optic sheath enhancement, negative CSF OCBs, (term implies \\
\hline & neuropathy (CRION) & granulomatous pathology) \\
\hline & Autoimmune $\mathrm{ON}$ & $\begin{array}{l}\text { Relapses off steroids, similar to CRION but implies an autoimmune, } \\
\text { nongranulomatous pathology }\end{array}$ \\
\hline & $\begin{array}{l}\text { Acute disseminated } \\
\text { encephalomyelitis (ADEM) }\end{array}$ & Bilateral, additional neurology, multiple lesions on MRI all enhancing \\
\hline \multirow[t]{8}{*}{ INFECTIOUS } & Lyme & $\begin{array}{l}\text { History of exposure, erythema chronicum migrans, radiculo-neuropathy, } \\
\text { heart and joints involved, neuroretinitis, vitritis, CSF cells }\end{array}$ \\
\hline & Syphilis & $\begin{array}{l}\text { Risk factors, genital ulcers, rash, involvement of other neurological } \\
\text { systems (cord especially dorsal columns, cortex), neuroretinitis, vitritis }\end{array}$ \\
\hline & Viral (EBV, CMV, HIV, others) & Prodrome, risk factors, polysystem involvement, vitritis, CSF cells \\
\hline & Tuberculosis & History of exposure, vitritis, abnormal CXR \\
\hline & Toxoplasmosis & Retinal or papillary lesion usually visible on fundoscopy \\
\hline & Toxocariasis & Neuroretinitis, eosinophilia \\
\hline & Bartonella (cat scratch) & History of exposure, respiratory involvement, neuroretinitis \\
\hline & Histoplasmosis & Respiratory symptoms, neuroretinitis \\
\hline POSTINFECTIOUS & & Commonly children, bilateral \\
\hline
\end{tabular}

Note: The term "CSF cells" refers to an increased number of white cells in the cerebrospinal fluid (the normal reference range in most laboratories is $<5$ white cells per mm ${ }^{3}$ ). Abbreviations: ANA, antinuclear antibodies; CMV, cytomegalovirus; CSF, cerebrospinal fluid; CXR, chest radiograph; dsDNA, double stranded deoxyribonucleic acid; EBV, Epstein-Barr virus; HIV, human immunodeficiency virus; MRI, magnetic resonance imaging; OCB, oligoclonal bands. 
Typical ON may present as an isolated event, be a recurrent problem, or be followed later in life by inflammatory events elsewhere in the CNS. The occurrence of multiple events, disseminated in time and space within the CNS, defines MS. ${ }^{9} 10$ Subsequent events that are restricted to the optic nerves and spinal cord can be caused by neuromyelitis optica (NMO). ${ }^{11} \mathrm{ON}$ associated with NMO is often particularly severe and other atypical features may be present. The recent discovery of a pathogenic autoantibody has resulted in a realization that the clinical phenotype is wider than previously thought, and may include some patients with recurrent ON, without spinal cord involvement. ${ }^{12}$

The risk of recurrence of $\mathrm{ON}$ depends on the cause and length of follow-up, and was found to be $28 \%{ }^{13}$ and $35 \%{ }^{14}$ for typical ON, at five and ten years, respectively.

\section{Clinical features}

Typical ON usually presents with subacute painful loss of vision in one eye. The pain is sometimes ill defined at first, but then usually localizes in or around one eye. It is commonly worse with eye movements. The severity of the pain varies, but it is unusual for it to disturb sleep, or last longer than a few days.

This is concurrent with, or followed by, a reduction of vision in the same eye. Affected patients' reports of the early stages of visual loss are: "like looking through frosted glass" or "as if there is a smear of grease on my eye". The severity of visual loss is very variable, ranging from minimal blurring to inability to perceive light. Flashes of light on eye movements, called phosphenes or photopsias, may be reported. Visual loss usually progresses over a few days to two weeks, remains at a nadir for a period of days, and then begins to improve. Sometimes, during this period of recovery, patients notice that vision temporarily worsens with a rise in body temperature, for example, after a hot shower or exercise, termed Uhthoff's symptom. ${ }^{15}$ This can also occasionally be the presenting symptom. Pulfrich's phenomenon, an anomalous depth perception sensitive to objects in motion, may also be reported. ${ }^{16}$ Patients may describe persistent difficulties in certain sporting activities, for example, difficulty judging the trajectory of a tennis ball, despite near normal visual acuity.

Clinical signs in the acute stage include reduced monocular visual acuity in $90 \%$ of cases. ${ }^{5}$ Tests of low contrast acuity are sensitive at detecting deficits in the minority of people who have mild visual loss and are abnormal in $98 \%$. Color vision is characteristically affected, sometimes more than other aspects of vision, and abnormalities on testing are detectable in $94 \%$ of patients in the acute stage. The spectral location of color deficits varies between patients and no consistent pattern is seen. ${ }^{17}$

Visual field defects are detectable in $97 \%$ of people. ${ }^{18}$ Due to the patchy nature of the underlying pathology, a wide variety of defects are possible. The most commonly encountered is a diffuse pattern of visual loss, seen in $48 \%$ of cases. ${ }^{19}$ Central field abnormality is seen more commonly than peripheral deficit, and peripheral defects may improve more rapidly. ${ }^{18}$ Isolated central and centrocecal scotomas occur in $8 \% .{ }^{19}$ Altitudinal defects are seen in $20 \%$ and various other types make up $23 \%$. Chiasmal and retrochiasmal defects are less frequent, seen in only $3 \%$ of people. Incidental abnormalities of the unaffected eye are common. ${ }^{19,20}$ Recovery of visual field function is generally good and does not differ between diffuse and localized field defects. ${ }^{21}$

Nearly all patients with unilateral ON have a relative afferent pupillary defect (RAPD), ${ }^{22}$ and this was an inclusion criterion in the North American Optic Neuritis Treatment Trial (ONTT), ${ }^{5}$ the largest clinical study of $\mathrm{ON}$, from which the symptom prevalences, cited above, were derived. Fundoscopy reveals a diffusely swollen disc in $35 \%$, or may be normal, particularly if inflammation solely affects the posterior part of the nerve (retrobulbar $\mathrm{ON})$. The retina is typically normal, except for perivenous sheathing (retinal periphlebitis), which is occasionally seen, and is associated with a higher risk of MS. ${ }^{23}$ After around six weeks, the optic disc may become pale due to atrophy of the optic nerve.

There are some ethnic differences in the clinical profile. Acute disc swelling is more common in Japanese patients than Americans, and pain was less frequent in a Japanese cohort, compared to the patients in the ONTT. ${ }^{24}$

Recovery usually begins within the first month. In the ONTT, $79 \%$ of people had started to improve by three weeks and $93 \%$ by five weeks. ${ }^{25}$ Improvements may continue after this, especially in patients who have been severely affected and those in whom recovery is slower, and significant improvement may continue for up to six months. Subtle improvement may still be detectable a year or more after the acute attack, although by this time the patients do not tend to notice changes relevant to function. Most patients make a good functional visual recovery, improving to a Snellen acuity of $20 / 40$ or better, but around $5 \%-10 \%$ of people fail to recover. ${ }^{26}$ Many more complain of residual symptoms and deficits of acuity, fields, color vision, and, especially, low contrast acuity may be detectable for years afterwards. ${ }^{13,27}$ 
Atypical presentations occur and, whilst these may be seen in typical ON, they can be a marker of a more unusual alternative etiology of ON (Table 1), or in other conditions mimicking ON (Table 2). Atypical features include absence of pain, which is seen in only $8 \%$ of people with typical $\mathrm{ON},{ }^{5}$ marked swelling of the nerve with retinal exudates and peripapillary hemorrhages, evidence of neuroretinitis, such as a macular star, severe visual loss to no light perception, progression of visual loss or pain for more than two weeks, and lack of recovery after three weeks. ${ }^{28-30}$ Bilateral ON may occur, either simultaneously or sequentially, ${ }^{31}$ which would also be an unusual feature in typical ON. ${ }^{29}$ These "red flags" should prompt consideration of an atypical cause of $\mathrm{ON}$, or an alternative diagnosis, and are summarized in Table 3.

\section{Diagnosis and association with multiple sclerosis}

The diagnosis of typical ON is essentially clinical, based upon a characteristic clinical presentation, with consistent physical signs, in an appropriate demographic group. A careful history and physical examination should be performed to identify any previous neurological episodes, and to look for involvement of other neurological systems, which may indicate an underlying diagnosis of MS. In typical ON with recovery, further confirmatory investigations are not mandatory. Patients are informed of the association with MS. Magnetic resonance imaging (MRI) of the brain helps to stratify the risk of future inflammatory events, and is generally discussed with patients. If MRI shows radiological evidence of asymptomatic demyelination in the brain (Figure 1), which has been reported in $59 \%$ of patients presenting with isolated $\mathrm{ON},{ }^{32}$ and $70 \%$ of clinically isolated syndromes in general, ${ }^{33}$ then the risk of developing MS is higher. Visual recovery should be assessed one month after the acute episode.

If atypical features are present, urgent further investigations are indicated to exclude the differential diagnoses listed in Tables 1 and 2. The choice of investigations depends upon the exact clinical picture, but should include MRI of the optic nerves, especially to rule out compressive causes of optic neuropathy, and also to assess for signal change within the nerves (Figure 2). Computerized tomography (CT) of the orbits is sometimes helpful in delineating bony orbital lesions. Cerebrospinal fluid examination is required to detect cells (in infective and atypical inflammatory causes), elevated protein, and oligoclonal bands. Blood tests and other paraclinical investigations may be indicated if atypical infective or inflammatory ON is suspected (Table 4). If other specific differential diagnoses are considered likely, further specialized tests may be necessary (eg, toxin screens, serum B12, mitochondrial genetics for Leber's hereditary optic neuropathy, orbital ultrasound for posterior scleritis, optical coherence tomography, fluorescein angiography, and electroretinography for retinal disease).

Table 2 Mimics of optic neuritis: Other causes of optic neuropathy, retinal, scleral, and orbital disease

\begin{tabular}{|c|c|c|}
\hline Anatomical region & Condition & Clinical clues \\
\hline \multirow[t]{2}{*}{ Retina } & Central serous retinopathy (CSR) & $\begin{array}{l}\text { Painless central blurring and photopsia, usually good } \\
\text { recovery, macular abnormalities on fundoscopy }\end{array}$ \\
\hline & $\begin{array}{l}\text { Big blind spot syndrome/acute zonal occult } \\
\text { outer retinopathy (AZOOR) }\end{array}$ & $\begin{array}{l}\text { Painless enlargement of the blind spot, usually self-limiting, } \\
\text { sometimes associated with disc swelling, color vision } \\
\text { preserved }\end{array}$ \\
\hline Sclera & Posterior scleritis & $\begin{array}{l}\text { Severe pain wakes patient from sleep, visual symptoms } \\
\text { not prominent, proptosis, disc swelling }\end{array}$ \\
\hline \multirow[t]{7}{*}{ Optic nerve } & $\begin{array}{l}\text { Ischemic optic neuropathy (may be related to } \\
\text { giant cell arteritis - in which case may be } \\
\text { painful - or diabetic papillitis) }\end{array}$ & $\begin{array}{l}\text { Painless, acute, disc swelling invariably present during the } \\
\text { acute episode, altitudinal field defect, poor recovery }\end{array}$ \\
\hline & Optic nerve compression & $\begin{array}{l}\text { Progressive symptoms, usually painless (except aneurysms, } \\
\text { mucocele) }\end{array}$ \\
\hline & Leber's hereditary optic neuropathy & $\begin{array}{l}\text { Usually men, bilateral simultaneous or sequential optic } \\
\text { neuropathy, painless }\end{array}$ \\
\hline & Toxic optic neuropathy & $\begin{array}{l}\text { Methanol poisoning: sometimes seen in alcohol dependent } \\
\text { patients, history of exposure }\end{array}$ \\
\hline & & Tobacco/alcohol ambylopia: painless, bilateral \\
\hline & Nutritional optic neuropathy & BI2 deficiency: risks for malabsorption, painless, bilateral \\
\hline & Drug-induced & Ethambutol in treatment of TB \\
\hline Orbit & Orbital cellulitis & Proptosis, other cranial nerve involvement \\
\hline Other & Functional & Variability, no objective signs such as RAPD, normal VEPs \\
\hline
\end{tabular}

Abbreviations: RAPD, relative afferent papillary defect; TB, tuberculosis; VEP, visual evoked potentials. 
Table 3 "Red flags" in the diagnosis of optic neuritis, leading to consideration of atypical causes or mimics

\begin{tabular}{lll}
\hline Feature & Red flag & Consider \\
\hline Demographic & African or Asian ethnicity & Sarcoidosis, lupus, TB \\
& Children & Postinfectious ON \\
Older people & Ischemic optic neuropathy \\
Past medical history & History of cancer (especially breast, lymphoma) & Metastatic optic nerve compression \\
Family history & Positive FH & Leber's hereditary optic neuropathy \\
Symptoms & Absence of pain & Ischemic ON, most causes of optic \\
& Severe pain waking from sleep & nerve compression, CSR \\
& Bilateral ON & Posterior scleritis, atypical inflammatory \\
& & especially CRION and sarcoidosis, infections \\
Signs & Atypical inflammatory, infections, Leber's, \\
& Severe visual loss & postinfectious/postvaccine, ADEM \\
& on fundoscopy & Atypical ON \\
Vitritis & Atypical inflammatory causes \\
& Neuroretinitis & eg, sarcoidosis, SLE. Infections \\
& Sarcoid, infections \\
Recovery & CSR, Lyme, syphilis, viruses, cat scratch \\
& Persistent pain $>2$ weeks & disease, toxocariasis, histoplasmosis, sarcoid \\
& & Aneurysmal or mucocele compression, \\
& Progressive visual loss $>2$ weeks & posterior scleritis, atypical inflammation, \\
infections
\end{tabular}

Abbreviations: ADEM, acute disseminated encephalomyelitis; CRION, chronic relapsing inflammatory optic neuritis; CSR, central serous retinopathy; SLE, systemic lupus erythematosus; TB, tuberculosis.

\section{Treatment of acute typical $\mathrm{ON}$}

At present, no therapy has been shown to improve long-term visual outcome in typical ON. Corticosteroids shorten the duration of the attack, but the consensus of several studies and a meta-analysis is that they do not appear to change the long-term outcome. ${ }^{34-39}$ Steroids have a risk of side effects, even if used short-term, including mood change, weight gain, insomnia, pancreatitis, avascular osteonecrosis, and psychosis. ${ }^{29}$ In the UK, corticosteroids tend to be reserved for patients with atypical features, coincident problems in the fellow eye, if pain is particularly severe, or at the patient's request, although practice varies in different countries. Intravenous methylprednisolone

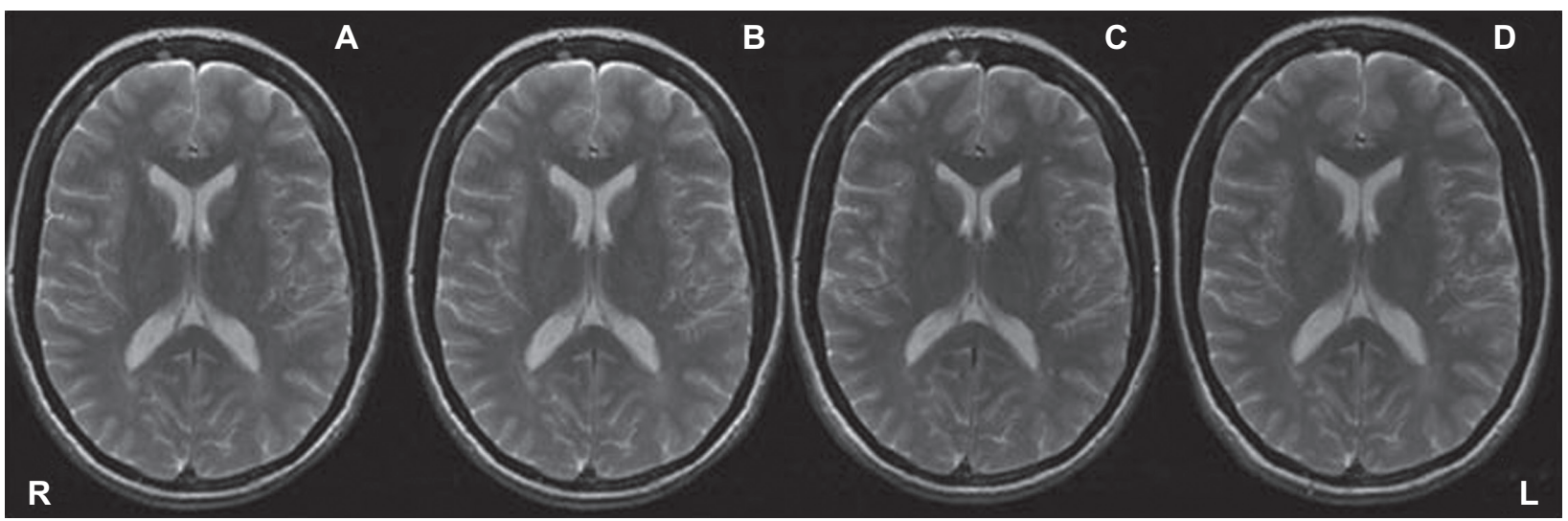

Figure I Serial axial brain MRI from a young woman with clinically isolated ON, taken over a 12 month period, demonstrating subtle demyelinating lesions. The presence of brain lesions is associated with a higher risk of MS after an isolated attack of typical ON, if the lesions are in a typical distribution for demyelinating disease, and excessive for the patient's age. T2-weighted high signal abnormalities are seen in the white matter of the brain at the time of presentation with ON (A), and new lesions develop over the course of the year at three months (B), six months (C), and 12 months (D). At presentation, periventricular lesions are seen on the right, adjacent to the frontal and occipital horns. In addition, there is ill-defined signal change adjacent to the occipital horn of the left lateral ventricle. A more peripheral left frontal lesion is seen. New lesions are seen at six months, with the appearance of a right frontal juxtacortical lesion, and a new discrete lesion adjacent to the occipital horn of the left lateral ventricle. At 12 months, the left frontal lesion appears less conspicuous.

Abbreviations: R, right; L, left. 


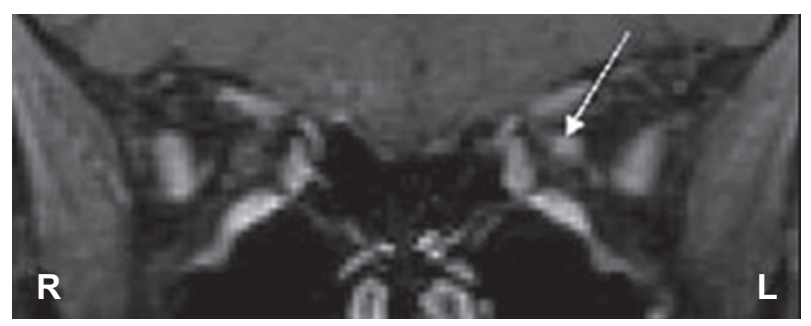

Figure 2 Coronal post-triple dose gadolinium TI-weighted MRI demonstrating left optic nerve enhancement (arrow).

Abbreviations: $R$, right; $L$, left.

tends to be preferred ${ }^{34}$ (typically $1 \mathrm{~g}$ a day intravenously for three days without an oral taper). A prospective small trial showed that oral methylprednisolone $500 \mathrm{mg}$ a day for five days (with an oral taper) hastened visual recovery but did not affect outcome, so this may be a viable alternative. ${ }^{40}$

Beta-interferon and glatiramer acetate are established disease-modifying therapies in MS, which are known to reduce the rate of relapses by around a third over two years. ${ }^{41-43}$ The indications for their use following a single neurological episode suggestive of MS, such as ON, is still debated. In the USA, disease-modifying drugs are often prescribed after clinically isolated ON if the brain MRI is abnormal, indicating a higher risk of MS. ${ }^{44}$ There is evidence that this delays the onset of the disease, ${ }^{45-49}$ which is consistent with their known efficacy in preventing a proportion of relapses in established MS. Some authorities argue that early treatment to prevent relapses may help prevent subsequent axonal damage. There may be an effect on short-term disability, ${ }^{50}$ but any long-term benefits have yet to be reliably proven. In addition, in a significant proportion of patients with $\mathrm{ON}$, no further clinical symptoms emerge for many years, and not all patients with an abnormal brain MRI subsequently develop MS, even after 30 years of follow up. ${ }^{51}$
In the UK, disease-modifying therapies are not used routinely following clinically isolated $\mathrm{ON}$, and two clinical relapses are generally required before institution of treatment. The other treatments licensed in MS, mitoxantrone ${ }^{52,53}$ and natalizumab, ${ }^{54,55}$ are reserved for patients with severe, aggressive disease because of the risk of serious side effects, and do not have a role in the management of clinically isolated ON.

Treatment with steroids does not influence the subsequent long-term risk of MS. Although two year follow-up data from the ONTT initially suggested that intravenous methylprednisolone might delay the second, MS-defining relapse in comparison with oral prednisolone or placebo, ${ }^{56}$ this was not sustained at three years, or fifteen years, ${ }^{57}$ and therefore steroids are not used for this purpose.

Intravenous immunoglobulin has been tried in patients with persistent visual loss, but this did not result in any clinically significant benefits in randomized placebo-controlled trials. Both an American Phase II study of 55 patients $^{58}$ and a Danish placebo-controlled trial of 68 patients ${ }^{59}$ used visual outcome at six months as an outcome measure and found no benefit.

\section{Treatment of atypical ON}

Treatment of atypical ON depends on the cause, and a detailed discussion of the management of systemic inflammatory and autoimmune conditions is outside the scope of this review. Infective $\mathrm{ON}$ requires appropriate antimicrobials. Atypical inflammatory causes require large doses of steroids (typically $1 \mathrm{~g}$ per day of intravenous methylprednisolone is used), and immunosuppressants targeted towards the underlying disease process, for example, cyclophosphamide for lupus, ${ }^{60,61}$ or azathioprine, mycophenolate, or rituximab for

Table 4 Specific tests to consider in atypical ON, in addition to MRI of the optic nerves and brain and cerebrospinal fluid analysis

\begin{tabular}{ll}
\hline Suspected condition & Investigations to consider \\
\hline Neuromyelitis optica & Anti-aquaporin-4 antibodies \\
Sarcoidosis & Serum ACE, CXR ${ }^{+/-}$CT chest, (lymph node or other tissue biopsy) \\
Lupus erythematosus & Serum antinuclear antibodies, extractable nuclear antigens, anti-dsDNA antibodies, serum complement \\
Behçets & Skin pathergy test \\
CRION/Autoimmune ON & No specific tests - usually have negative CSF OCBs and antibodies. Defined by relapses when off steroids. \\
Lyme & Borrelia serology, ECG \\
Syphilis & Treponemal serology (eg, VDRL) \\
Viral & Specific serology, CD4 count if HIV positive \\
Tuberculosis & CXR, CSF for TB culture \\
Toxoplasmosis & Serology \\
Cat scratch disease & Bartonella serology \\
\hline
\end{tabular}

Abbreviations: ACE, angiotensin converting enzyme; CSF, cerebrospinal fluid; CT, computerized tomogram; CXR, chest radiograph; dsDNA, double stranded deoxyribonucleic acid; ECG, electrocardiogram; FH, family history; HIV, human immunodeficiency virus; OCB, oligoclonal bands; TB, tuberculosis; VDRL, venereal diseases research laboratory. 
neuromyelitis optica. ${ }^{62}$ The administration of intravenous steroids should be supplemented with a prolonged oral tail. If high dose steroids are ineffective at restoring vision during the acute episode, then plasma exchange may be used. ${ }^{63}$ There is a lack of randomized trial evidence, and further studies are needed.

There can be difficulties in the management of recurrent inflammatory ON. In a proportion of patients ancillary investigations do not identify any specific underlying diagnosis. If steroid withdrawal results in further relapses, this syndrome is termed chronic relapsing inflammatory optic neuropathy (CRION), ${ }^{64}$ or autoimmune ON, depending on whether a granulomatous or nongranulomatous autoimmune etiology is thought most likely. A proportion of patients with recurrent $\mathrm{ON}$ subsequently develop $\mathrm{NMO}$, with a conversion rate of $21 \%$ reported in one study after six years of follow up. ${ }^{65}$ In another study, $20 \%$ of patients with recurrent $\mathrm{ON}$ were seropositive for anti-aquaporin- 4 antibodies, and 50\% of these seropositive patients developed NMO within the next nine years. ${ }^{66}$ This illustrates an increasing appreciation of the phenotypic spectrum of NMO, following the discovery of the anti-aquaporin-4 antibody. ${ }^{11,67-69}$ It appears that limited forms of NMO exist, and that the presence of antibodies is also associated with visual prognosis. ${ }^{12,66}$ Therefore, early diagnosis of NMO presenting as $\mathrm{ON}$ has become increasingly important, in order to institute appropriate treatment, such as rituximab. ${ }^{70}$

\section{Visual prognosis}

The majority of people with typical ON make a good visual recovery, even if visual loss is initially severe. ${ }^{25,71}$ Improvement usually begins in the first month. Outcome at six months is associated with the degree of initial visual loss, ${ }^{25}$ and with vision at one month. ${ }^{72}$ One year later, $95 \%$ of people have improved to Snellen 20/40 or better. ${ }^{26}$ After five years, 28\% of people in the ONTT had had a further attack, but $87 \%$ still had acuities of 20/25 or better, 94\% 20/40 or better, and $97 \% 20 / 200$ or better. ${ }^{13}$ Ten years later, $74 \%$ had a visual acuity of $20 / 20$ or better, and $92 \%$ and $97 \%$ still had acuities of 20/40 and 20/200 or better, respectively. ${ }^{14}$ Recently, the 15 year final follow-up results were reported, and $72 \%$ of patients still had acuities of 20/20 or better. ${ }^{73}$ However, many patients who are able to score well on the Snellen chart still have residual deficits of low contrast acuity, impaired color vision, and visual field defects. ${ }^{74}$ Most patients report that their vision is not quite as good as it was before, ${ }^{75}$ and this may impact on quality of life. ${ }^{76}$ No associations have been found between the degree of visual recovery and age, gender, ethnicity, abnormalities on brain $\mathrm{MRI},{ }^{25}$ visual evoked potential (VEP) parameters during the acute stage, ${ }^{77}$ or optic nerve MRI measures of myelination. ${ }^{78}$

The data regarding the influence of steroids on recurrence of ON are somewhat confusing. Surprisingly, in the ONTT, a weak effect was found suggesting that oral prednisolone was associated with a higher risk of recurrence of ON, compared to intravenous methylprednisolone or placebo. This is difficult to explain at the neurobiological level, and the statistical significance of this finding disappeared over time. ${ }^{14}$ Therefore, interpretation remains difficult. Low dose oral prednisolone is avoided by some clinicians for this reason. When steroids are prescribed to shorten the duration of $\mathrm{ON}$, methylprednisolone tends to be preferred.

\section{Neurological prognosis}

The risk of developing MS after typical ON depends predominantly on the length of follow-up, and whether the brain MRI at the time of presentation was normal. Five years after an attack of typical ON, $16 \%$ of people with a normal brain MRI had developed MS, compared with $51 \%$ of people who had three lesions or more. ${ }^{79}$ Ten years after onset, in the same cohort, the risk was reported as $22 \%$ if the initial MRI was normal, increasing to $56 \%$ if it was abnormal. ${ }^{28}$ Female gender, absence of optic disc swelling, and absence of atypical features were all associated with a higher risk profile. Other researchers have reported retinal vascular abnormalities, ${ }^{23}$ HLA-DR2 genotype, ${ }^{80}$ and the presence of oligoclonal bands in the cerebrospinal fluid ${ }^{81}$ as additional risk factors. Fifteen year follow up of the ONTT cohort subsequently reported conversion rates of $25 \%$ with a normal MRI, and $72 \%$ with an abnormal MRI. ${ }^{57}$ The longest reported follow-up is located in a Swedish study, in which an overall $40 \%$ conversion rate was found after 31 years. ${ }^{51}$

In a different study people with a variety of clinically isolated syndromes were assessed, 14 years after the acute attack. ${ }^{33}$ More than half of the patients had presented with $\mathrm{ON}$, and the remainder had transverse myelitis or brainstem syndromes. The authors reported conversion rates of $19 \%$ in people who had a normal MRI at baseline, increasing to $88 \%$ if the scan was abnormal.

If MS does subsequently develop, it is said to generally follow a more benign course if typical $\mathrm{ON}$ is the presenting symptom, rather than pyramidal or cerebellar symptoms. ${ }^{82}$ In the ONTT, 65\% of people had an Expanded Disability Status Score (EDSS) of 3.0 or less ten years later, ${ }^{83}$ and $14 \%$ had severe disability (EDSS of 6 or more, corresponding to needing a stick to walk $100 \mathrm{~m}$ ). 
Therefore, the majority of people have a favorable visual and neurological prognosis following typical ON. However, for the minority who fail to recover, treatment options are limited. It also remains somewhat unclear when it is optimal to intervene with disease modifying therapy after a single attack of typical ON. This is because the relationships between inflammation, demyelination, and neuroaxonal loss are incompletely understood. Recent researchers have focused on elucidating the mechanisms underlying damage and recovery in $\mathrm{ON}$, with a view to devising better therapies in the future.

\section{Investigating damage and recovery in $\mathrm{ON}$}

In recent years, much progress has been made in elucidating mechanisms of damage and recovery in typical ON. Our current level of understanding has been achieved by combining the results of pathological studies in humans, extrapolating data from work in MS, experimental allergic encephalomyelitis work in animals, and in vivo studies in patients with ON, using MRI, electrophysiology, and optical coherence tomography. During the acute stage, inflammation, ${ }^{84-86}$ which is predominantly T-cell mediated, and demyelination ${ }^{87-89}$ occur. These two distinct, but linked, processes have detrimental effects on neural conduction, which may lead to acute conduction blocks in the optic nerve, ${ }^{90}$ manifested clinically as visual loss. Inflammation is associated with edema. ${ }^{91}$ After a few weeks, inflammation, edema, and conduction block resolve and vision begins to recover. Redistribution of sodium channels also occurs. ${ }^{92}$ Subsequently, there is persistent demyelination, neuroaxonal loss, ${ }^{88,93-98}$ and probably gliosis. There are secondary effects on the rest of the visual pathway, which are incompletely understood, but may involve retrograde, Wallerian, and trans-synaptic degeneration. ${ }^{77,97,99-102}$ Atrophy is detectable in the optic nerve $\mathrm{e}^{91,96,103}$ and dynamic changes in MRI diffusion parameters occur, which reflect changes in myelin and axonal damage. ${ }^{104-107}$ Neuroaxonal loss occurs in the retinal nerve fiber layer and macula. ${ }^{97,98,103}$ Despite this, most patients make a good clinical recovery, which may reflect neuroaxonal redundancy, ${ }^{108}$ or an influence of repair mechanisms, such as remyelination ${ }^{78,109,110}$ or adaptive changes in the gray matter, known as neuroplasticity. ${ }^{103,111,112}$ Recently, it has been hypothesized that aggressive early immunosuppression in demyelinating disease may prevent the subsequent neuroaxonal loss thought to underpin later neurodegeneration, ${ }^{113}$ although further work is needed to support or refute this hypothesis.

\section{Future directions}

\section{Remyelination}

There is evidence that remyelination improves clinical function from experimental models of demyelination in rats. ${ }^{114}$ However, remyelination after $\mathrm{ON}$ in people occurs slowly, months to years after the initial insult, ${ }^{109,110,115}$ by which time most of the clinical improvement has already occurred. Recently, evidence has emerged that remyelination may also prevent subsequent degeneration of the axon, ${ }^{116}$ which has led to interest in remyelination as a therapeutic strategy to prevent neurodegeneration.

In both health and disease, maintenance of the myelin sheath is a dynamic process. Following demyelination, remyelination may occur spontaneously, ${ }^{117}$ through the action of oligodendrocytes recruited from precursor cells, expressing platelet-derived growth factor. ${ }^{118}$ The recruitment and differentiation of oligodendrocytes from these precursors appears to be critical for successful remyelination to occur. Sometimes remyelination fails, and this is either because oligodendrocytes are not present or, if present, are inactive. The reasons for this are incompletely understood, but animal work suggests that differentiation, rather than recruitment, of oligodendrocytes from precursors is the main problem in demyelinating disease. ${ }^{119}$ The migration of precursors to the demyelinated lesion appears to be impaired, perhaps through dysregulation of cellular signalling molecules, ${ }^{120}$ or aberrant clearance of myelin debris. ${ }^{121}$ At present, it remains unclear how these insights can be translated into facilitating remyelination in patients.

One potential therapeutic avenue is through the use of exogenous stem cells. Although remyelination is usually dependent on oligodendrocyte function in the CNS, it is also possible using a variety other different cell types, such as exogenous Schwann cells, ${ }^{122}$ olfactory ensheathing cells, ${ }^{123}$ and neural stem cells, derived from bone marrow. ${ }^{124}$ This led to the idea of using exogenous stem cells as a therapeutic strategy, which is discussed further in later sections.

\section{Adaptive plasticity}

It is likely that gray matter responses to an abnormal afferent input are associated with the degree of visual recovery. Several regions have been implicated. Results of early studies showed widely distributed changes in functional MRI responses to visual stimulation in extra-occipital cortex. ${ }^{125,126}$ More recently, researchers have implicated specific regions early after the acute episode as being crucial for visual recovery: the lateral occipital complexes, ${ }^{103,111}$ cuneus, ${ }^{127}$ 
and lateral geniculate nuclei. ${ }^{112}$ Therapeutic manipulation of the mechanisms underpinning adaptive plasticity may be possible in the future, and provide a novel target for future treatments. This could be through rehabilitation approaches, such as visual restitution therapy, which has been successfully applied to patients with visual field defects ${ }^{128}$ or by using drugs to enhance adaptive neuroplastic responses, or perhaps prevent maladaptive responses in patients who fail to recover.

\section{Stem cells}

The initial hope was that stem cells would enhance neural repair, perhaps through a mechanism of remyelination, and it has been hypothesized that remyelination may prevent future axonal damage. In practice, results from animal models are proving that the mechanism of action of stem cells is much more complex. It appears that therapeutic effects are exerted through several mechanisms, and that immunomodulatory effects may be more influential than actual cell replacement. ${ }^{129,130}$ More work is needed to decipher the complex cell biology, but there remains great optimism in the research community about the potential of stem cells. Preliminary pilot studies to investigate safety and proof-of-principle are underway in patients with MS-associated ON. ${ }^{131}$

\section{Conclusion}

$\mathrm{ON}$ is essentially a clinical diagnosis, and a careful history and examination is critical in differentiating the common phenotype of typical ON from rarer, atypical, steroid-responsive, and infective causes. Typical $\mathrm{ON}$ is usually self-limiting and the majority of patients recover without treatment, although steroids are considered in patients who stand to benefit from a more rapid recovery. MRI is useful in stratifying the subsequent risk of MS in typical ON. Atypical ON requires urgent investigation and a more aggressive therapeutic approach, using high dose steroids, immunosuppression, and sometimes plasma exchange. For the minority of patients with typical $\mathrm{ON}$ who fail to recover, there are at present no effective treatments. Research insights into the pathophysiology of ON may help develop more effective therapies in the future, perhaps by exploiting reparative processes, such as remyelination and neuroplasticity, or through new methods of immunomodulation. Investigations into the potential utility of stem cells are underway.

\section{Disclosure}

The authors report no conflicts of interest in this work.

\section{References}

1. McDonald BK, Cockerell OC, Sander JW, Shorvon SD. The incidence and lifetime prevalence of neurological disorders in a prospective community-based study in the UK. Brain. 2000;123:665-676.

2. Rodriguez M, Siva A, Cross SA, O’Brien PC, Kurland LT. Optic neuritis: a population-based study in Olmsted County, Minnesota. Neurology. 1995;45:244-250.

3. Jin YP, de Pedro-Cuesta J, Soderstrom M, Stawiarz L, Link H. Incidence of optic neuritis in Stockholm, Sweden 1990-1995: I. Age, sex, birth and ethnic-group related patterns. J Neurol Sci. 1998;159:107-114.

4. Jin YP, de Pedro-Cuesta J, Soderstrom M, Link H. Incidence of optic neuritis in Stockholm, Sweden, 1990-1995: II. Time and space patterns. Arch Neurol. 1999;56:975-980.

5. Optic Neuritis Study Group. The clinical profile of optic neuritis. Experience of the Optic Neuritis Treatment Trial. Arch Ophthalmol. 1991;109:1673-1678.

6. Sorensen TL, Frederiksen JL, Bronnum-Hansen H, Petersen HC. Optic neuritis as onset manifestation of multiple sclerosis: a nationwide, long-term survey. Neurology. 1999;53:473-478.

7. Ascherio A, Munger KL. Environmental risk factors for multiple sclerosis. Part I: the role of infection. Ann Neurol. 2007;61:288-299.

8. Ascherio A, Munger KL. Environmental risk factors for multiple sclerosis. Part II: Noninfectious factors. Ann Neurol. 2007;61:504-513.

9. McDonald WI, Compston A, Edan G, et al. Recommended diagnostic criteria for multiple sclerosis: guidelines from the International Panel on the diagnosis of multiple sclerosis. Ann Neurol. 2001;50:121-127.

10. Polman $\mathrm{CH}$, Reingold SC, Edan G, et al. Diagnostic criteria for multiple sclerosis: 2005 revisions to the "McDonald Criteria". Ann Neurol. 2005;58:840-846.

11. Wingerchuk DM, Lennon VA, Pittock SJ, Lucchinetti CF, Weinshenker BG. Revised diagnostic criteria for neuromyelitis optica. Neurology. 2006;66:1485-1489.

12. Matthews LAE, Baig F, Palace J, Turner MR. The borderland of neuromyelitis optica. Pract Neurol. 2009;9:335-340.

13. Optic Neuritis Study Group. Visual function 5 years after optic neuritis: experience of the Optic Neuritis Treatment Trial. Arch Ophthalmol. 1997;115:1545-1552.

14. Beck RW, Gal RL, Bhatti MT, et al. Optic Neuritis Study Group. Visual function more than 10 years after optic neuritis: experience of the optic neuritis treatment trial. Am J Ophthalmol. 2004;137:77-83.

15. Selhorst JB, Saul RF. Uhthoff and his symptom. J Neuroophthalmol. 1995;15:63-69.

16. Slagsvold JE. Pulfrich pendulum phenomenon in patients with a history of acute optic neuritis. Acta Ophthalmol (Copenh). 1978;56: 817-826.

17. Schneck ME, Haegerstrom-Portnoy G. Color vision defect type and spatial vision in the optic neuritis treatment trial. Invest Ophthalmol Vis Sci. 1997;38:2278-2289.

18. Keltner JL, Johnson CA, Spurr JO, Beck RW. Comparison of central and peripheral visual field properties in the optic neuritis treatment trial. Am J Ophthalmol. 1999;128:543-553.

19. Keltner JL, Johnson CA, Spurr JO, Beck RW. Baseline visual field profile of optic neuritis. The experience of the optic neuritis treatment trial. Optic Neuritis Study Group. Arch Ophthalmol. 1993;111: 231-234.

20. Beck RW, Kupersmith MJ, Cleary PA, Katz B. Fellow eye abnormalities in acute unilateral optic neuritis. Experience of the optic neuritis treatment trial. Ophthalmology. 1993;100:691-697.

21. Fang JP, Lin RH, Donahue SP. Recovery of visual field function in the optic neuritis treatment trial. Am J Ophthalmol. 1999;128: 566-572.

22. Cox TA, Thompson HS, Corbett JJ. Relative afferent pupillary defects in optic neuritis. Am J Ophthalmol. 1981;92:685-690.

23. Lightman S, McDonald WI, Bird AC, et al. Retinal venous sheathing in optic neuritis: its significance for the pathogenesis of multiple sclerosis. Brain. 1987;110:405-414. 
24. Wakakura M, Minei-Higa R, Oono S, et al. Baseline features of idiopathic optic neuritis as determined by a multicenter treatment trial in Japan. Optic Neuritis Treatment Trial Multicenter Cooperative Research Group (ONMRG). Jpn J Ophthalmol. 1999;43:127-132.

25. Beck RW, Cleary PA, Backlund JC. The course of visual recovery after optic neuritis. Experience of the Optic Neuritis Treatment Trial. Ophthalmol. 1994;101:1771-1778.

26. Beck RW, Cleary PA. Optic neuritis treatment trial. One-year follow-up results. Arch Ophthalmol. 1993;111:773-775.

27. Frederiksen JL, Sorensen TL, Sellebjerg FT. Residual symptoms and signs after untreated acute optic neuritis. A one-year follow-up. Acta Ophthalmol Scand. 1997;75:544-547.

28. Beck RW, Trobe JD, Moke PS, et al. Optic Neuritis Study Group. High- and low-risk profiles for the development of multiple sclerosis within 10 years after optic neuritis: experience of the optic neuritis treatment trial. Arch Ophthalmol. 2003;121:944-949.

29. Hickman SJ, Dalton CM, Miller DH, Plant GT. Management of acute optic neuritis. Lancet. 2002;360:1953-1962.

30. Shams PN, Plant GT. Optic neuritis: a review. Int MS J. 2009;16: 82-89.

31. Pirko I, Blauwet LK, Lesnick TG, Weinshenker BG. The natural history of recurrent optic neuritis. Arch Neurol. 2004;61:1401-1405.

32. Beck RW, Arrington J, Murtagh FR, Cleary PA, Kaufman DI. Brain magnetic resonance imaging in acute optic neuritis. Experience of the Optic Neuritis Study Group. Arch Neurol. 1993;50:841-846.

33. Brex PA, Ciccarelli O, O'Riordan JI, Sailer M, Thompson AJ, Miller DH. A longitudinal study of abnormalities on MRI and disability from multiple sclerosis. N Engl J Med. 2002;346:158-164.

34. Beck RW, Cleary PA, Anderson MM Jr, et al. A randomized, controlled trial of corticosteroids in the treatment of acute optic neuritis. The Optic Neuritis Study Group. N Engl J Med. 1992;326:581-588.

35. Beck RW, Cleary PA. Optic neuritis treatment trial. One-year follow-up results. Arch Ophthalmol. 1993;111:773-775.

36. Kapoor R, Miller DH, Jones SJ, et al. Effects of intravenous methylprednisolone on outcome in MRI-based prognostic subgroups in acute optic neuritis. Neurology. 1998;50:230-237.

37. Wakakura M, Mashimo K, Oono S, et al. Multicenter clinical trial for evaluating methylprednisolone pulse treatment of idiopathic optic neuritis in Japan. Optic Neuritis Treatment Trial Multicenter Cooperative Research Group (ONMRG). Jpn J Ophthalmol. 1999;43:133-138.

38. Brusaferri F, Candelise L. Steroids for multiple sclerosis and optic neuritis: a meta-analysis of randomized controlled clinical trials. J Neurol. 2000;247:435-442.

39. Vedula SS, Brodney-Folse S, Gal RL, Beck R. Corticosteroids for treating optic neuritis. Cochrane Database Syst Rev. 2007;(1): CD001430.

40. Sellebjerg F, Nielsen HS, Frederiksen JL, Olesen J. A randomized, controlled trial of oral high-dose methyprednisolone in acute optic neuritis. Neurology. 1999;52(7):1479-1484.

41. IFNB Multiple Sclerosis study group. Interferon beta-1b is effective in relapsing remitting multiple sclerosis. I. Clinical results of a multicenter, randomized, double-blind, placebo-controlled trial. The IFNB Multiple Sclerosis study group. Neurology. 1993;43:555-561.

42. Johnson KP, Brooks BR, Cohen JA, et al. Copolymer 1 reduces relapse rate and improves disability in relapsing-remitting multiple sclerosis: results of a phase III multicenter, double-blind placebo-controlled trial. The Copolymer 1 Multiple Sclerosis Study Group. Neurology. 1995;45:1268-1276.

43. PRISMS study group. Randomised double-blind placebo-controlled study of interferon-beta-1a in relapsing/remitting multiple sclerosis. PRISMS (Prevention of relapses and disability by transected beta-1a subcutaneously in multiple sclerosis) Study Group. Lancet. 1998;352: 1498-1504.

44. Balcer LJ. Clinical practice. Optic neuritis. N Engl J Med. 2006;354: 1273-1280.

45. Jacobs LD, Beck RW, Simon JH, et al. Intramuscular interferon beta-1a therapy initiated during a first demyelinating event in multiple sclerosis. CHAMPS Study Group. N Engl J Med. 2000;343:898-904.
46. Comi G, Filippi M, Barkhof F, et al. Effect of early interferon treatment on conversion to definite multiple sclerosis: a randomised study. Lancet. 2001;357:1576-1582.

47. Beck RW, Chandler DL, Cole SR, et al. Interferon beta-1a for early multiple sclerosis: CHAMPS trial subgroup analyses. Ann Neurol. 2002;51:481-490.

48. Kappos L, Polman CH, Freedman MS, et al. Treatment with interferon beta-1b delays conversion to clinically definite and McDonald MS in patients with clinically isolated syndromes. Neurology. 2006;67: 1242-1249.

49. Comi G, Martinelli V, Rodegher M, et al. PreCISe study group. Effect of glatiramer acetate on conversion to clinically definite multiple sclerosis in patients with clinically isolated syndrome (PreCISe study): a randomised, double-blind, placebo-controlled trial. Lancet, 2009;374: 1503-1511.

50. Kappos L, Freedman MS, Polman CH, et al. Effect of early versus delayed interferon beta- $1 \mathrm{~b}$ treatment on disability after a first clinical event suggestive of multiple sclerosis: a 3-year follow-up analysis of the BENEFIT study. Lancet. 2007;370:389-397.

51. Nilsson P, Larsson EM, Maly-Sundgren P, Perfekt R, SandbergWollheim M. Predicting the outcome of optic neuritis: evaluation of risk factors after 30 years of follow-up. J Neurol. 2005;252:396-402.

52. LePage E, Leray E, Taurin G, Coustans M, Chaperon J, Edan G. Mitoxantrone as induction therapy in aggressive relapsing remitting multiple sclerosis: a descriptive analysis of 100 consecutive patients. Rev Neurol (Paris). 2006;162:185-194.

53. LePage E, Leray E, Taurin G, et al. Mitoxantrone as induction treatment in aggressive relapsing remitting multiple sclerosis: treatment response factors in a 5 year follow-up observational study of 100 consecutive patients. J Neurol Neurosurg Psychiatry. 2008;79:52-56.

54. Polman CH, O'Connor PW, Havrdova E, et al. A randomized, placebocontrolled trial of natalizumab for relapsing multiple sclerosis. $\mathrm{NEngl}$ J Med. 2006;354:899-910.

55. Rudick RA, Stuart WH, Calabresi PA, et al. Natalizumab plus interferon beta-1a for relapsing multiple sclerosis. $N$ Engl J Med. 2006;354:911-923.

56. Beck RW, Cleary PA, Trobe JD, et al. The effect of corticosteroids for acute optic neuritis on the subsequent development of multiple sclerosis. N Engl J Med. 1993;329:1764-1769.

57. Optic Neuritis Study Group. Multiple sclerosis risk after optic neuritis: final optic neuritis treatment trial follow-up. Arch Neurol. 2008; 65:727-732.

58. Noseworthy JH, O'Brien PC, Petterson TM, et al. A randomized trial of intravenous immunoglobulin in inflammatory demyelinating optic neuritis. Neurology. 2001;56:1514-1522.

59. Roed HG, Langkilde A, Sellebjerg F, et al. A double-blind, randomized trial of IV immunoglobulin treatment in acute optic neuritis. Neurology. 2005;64:804-810.

60. Trevisani VF, Castro AA, Neves Neto JF, Atallah AN. Cyclophosphamide versus methyprednisolone for treating neuropsychiatric involvement in systemic lupus erythematosus. Cochrane Database Syst Rev. 2006;19:CD002265.

61. Joseph FG, Scolding NJ. Neurolupus. Pract Neurol. 2010;10:4-15.

62. Wingerchuk D, Weinshenker B. Neuromyelitis optica. Curr Treat Opt Neurol. 2008;10:55-56.

63. Ruprecht K, Klinker E, Dintelmann T, Rieckmann P, Gold R. Plasma exchange for severe optic neuritis: treatment of 10 patients. Neurol. 2004;63:1081-1083.

64. Kidd D, Burton B, Plant GT, Graham EM. Chronic relapsing inflammatory optic neuropathy (CRION). Brain. 2003;126:276-284.

65. De Seze J, Arndt C, Jeanjean L, et al. Relapsing inflammatory optic neuritis: is it neuromyelitis optica? Neurology. 2008;70:2075-2076.

66. Matiello M, Lennon VA, Jacob A, et al. NMO-IgG predicts the outcome of recurrent optic neuritis. Neurology. 2008;70:2197-2200.

67. Lennon VA, Wingerchuk DM, Kryzer TJ, et al. A serum autoantibody marker of neuromyelitis optica: distinction from multiple sclerosis. Lancet. 2004;364:2106-2112. 
68. Weinshenker BG, Wingerchuk DM, Vukusic S, et al. Neuromyelitis optica IgG predicts relapse after longitudinally extensive transverse myelitis. Ann Neurol. 2006;59:566-569.

69. Wingerchuk DM, Lennon VA, Lucchinetti CF, Pittock SJ, Weinshenker BG. The spectrum of neuromyelitis optica. Lancet Neurol. 2007;6:805-815.

70. Jacob A, Weinshenker BG, Violich I, et al. Treatment of neuromyelitis optica with rituximab: retrospective analysis of 25 patients. Arch Neurol. 2008;65:1443-1448.

71. Slamovitis TL, Rosen CE, Cheng KP, Striph GG. Visual recovery in patients with optic neuritis and visual loss to no light perception. Am J Ophthalmol. 1991;111:209-214.

72. Kupersmith MJ, Gal RL, Beck RW, Xing D, Miller N. Visual function at baseline and 1 month in acute optic neuritis: predictors of visua outcome. Neurology. 2007;69:508-514.

73. Optic Neuritis Study Group. Visual function 15 years after optic neuritis: a final follow-up report from the Optic Neuritis Treatment Trial. Ophthalmology. 2008;115:1079-1082.

74. Fleishman JA, Beck RW, Linares OA, Klein JW. Deficits in visual function after resolution of optic neuritis. Ophthalmology. 1987;94:1029-1035.

75. Cleary PA, Beck RW, Bourque LB, Backlund JC, Miskala PH. Visual symptoms after optic neuritis. Results from the Optic Neuritis Treatment Trial. J Neuroophthalmol. 1997;17:18-23.

76. Noble J, Forooghian F, Sproule M, Westall C, O'Connor P. Utility of the National Eye Institute VFQ-25 questionnaire in a heterogeneous group of multiple sclerosis patients. Am J Ophthalmol. 2006;142:464-468.

77. Hickman SJ, Toosy AT, Miszkiel KA, et al. Visual recovery following acute optic neuritis-a clinical, electrophysiological and magnetic resonance imaging study. J Neurol. 2004;251:996-1005.

78. Hickman SJ, Toosy AT, Jones SJ, et al. Serial magnetization transfer imaging in acute optic neuritis. Brain. 2004;127:692-700.

79. Optic Neuritis Study Group. The 5-year risk of MS after optic neuritis Experience of the optic neuritis treatment trial. Optic Neuritis Study Group. Neurology. 1997;49:1404-1413.

80. Hauser SL, Oksenberg JR, Lincoln R, et al. Interaction between HLADR2 and abnormal brain MRI in optic neuritis and early MS. Optic Neuritis Study Group. Neurology. 2000;54:1859-1861.

81. Cole SR, Beck RW, Moke PS, Kaufman DI, Tourtellotte WW. The predictive value of CSF oligoclonal banding for MS 5 years after optic neuritis. Optic Neuritis Study Group. Neurology. 1998;51:885-887.

82. Ramsaransing G, Maurits N, Zwanikken C, De Keyser J. Early prediction of a benign course of multiple sclerosis on clinical grounds: a systematic review. Mult Scler. 2001;7:345-347.

83. Beck RW, Smith CH, Gal RL, et al. Optic Neuritis Study Group. Neurologic impairment 10 years after optic neuritis. Arch Neurol. 2004;61:1386-1389.

84. Youl BD, Turano G, Miller DH, et al. The pathophysiology of acute optic neuritis. An association of gadolinium leakage with clinical and electrophysiological deficits. Brain. 1991;114:2437-2450.

85. Guy J, Fitzsimmons J, Ellis EA, Beck B, Mancuso A. Intraorbital optic nerve and experimental optic neuritis. Correlation of fat suppression magnetic resonance imaging and electron microscopy. Ophthalmology. 1992;99:720-725.

86. Hohlfeld R, Wekerle H. Autoimmune concepts of multiple sclerosis as a basis for selective immunotherapy: from pipe dreams to (therapeutic) pipelines. Proc Natl Acad Sci U S A. 2004;101:14599-14606.

87. Rao NA, Tso MO, Zimmerman EL. Experimental allergic optic neuritis in guinea pigs: preliminary report. Invest Ophthalmol Vis Sci. 1977; 16:338-342.

88. Hayreh SS, Massanari RM, Yamada T, Hayreh SM. Experimental allergic encephalomyelitis. I. Optic nerve and central nervous system manifestations. Invest Ophthalmol Vis Sci. 1981;21:256-269.

89. Zhu B, Moore GR, Zwimpfer TJ, et al. Axonal cytoskeleton changes in experimental optic neuritis. Brain Res. 1999;824:204-217.

90. Felts PA, Baker TA, Smith KJ. Conduction in segmentally demyelinated mammalian central axons. J Neurosci. 1997;17:7267-7277.
91. Hickman SJ, Toosy AT, Jones SJ, et al. A serial MRI study following optic nerve mean area in acute optic neuritis. Brain. 2004;127:2498-2505.

92. Smith KJ. Sodium channels and multiple sclerosis: roles in symptom production, damage and therapy. Brain Pathol. 2007;17:230-242.

93. Toussaint D, Perier O, Verstappen A, Bervoets S. Clinicopathological study of the visual pathways, eyes, and cerebral hemispheres in 32 cases of disseminated sclerosis. J Clin Neuroophthalmol. $1983 ; 3: 211-220$

94. Trapp BD, Peterson J, Ransohoff RM, Rudick R, Mork S, Bo L. Axonal transection in the lesions of multiple sclerosis. $N$ Engl J Med. 1998;338:278-285.

95. Hickman SJ, Brierley CM, Brex PA, et al. Continuing optic nerve atrophy following optic neuritis: a serial MRI study. Mult Scler. 2002;8:339-342.

96. Inglese $\mathrm{M}$, Ghezzi A, Bianchi S, et al. Irreversible disability and tissue loss in multiple sclerosis: a conventional and magnetization transfer magnetic resonance imaging study of the optic nerves. Arch Neurol. 2002;59:250-255.

97. Trip SA, Schlottmann PG, Jones SJ, et al. Retinal nerve fiber layer axonal loss and visual dysfunction in optic neuritis. Ann Neurol. 2005;58:383-391.

98. Fisher JB, Jacobs DA, Markowitz CE, et al. Relation of visual function to retinal nerve fiber layer thickness in multiple sclerosis. Ophthalmol. 2006;113:324-332.

99. Evangelou N, Konz D, Esiri MM, Smith S, Palace J, Matthews PM. Size-selective neuronal changes in the anterior optic pathways suggest a differential susceptibility to injury in multiple sclerosis. Brain. 2001;124:1813-1820.

100. Ciccarelli O, Toosy AT, Hickman SJ, et al. Optic radiation changes after optic neuritis detected by tractography-based group mapping. Hum Brain Mapp. 2005;25:308-316.

101. Audoin B, Fernando KT, Swanton JK, Thompson AJ, Plant GT, Miller DH. Selective magnetization transfer ratio decrease in the visual cortex following optic neuritis. Brain. 2006;129:1031-1039.

102. Calabrese M, Atzori M, Bernardi V, et al. Cortical atrophy is relevant in multiple sclerosis at clinical onset. J Neurol. 2007;254:1212-1220.

103. Jenkins TM, Toosy AT, Ciccarelli O, et al. Neuroplasticity predicts outcome of optic neuritis independent of tissue damage. Ann Neurol. 2010;67:99-113.

104. Naismith RT, Xu J, Tutlam NT, et al. Disability in optic neuritis correlates with diffusion tensor-derived directional diffusivities. Neurology. 2009;72:589-594.

105. Kolbe S, Chapman C, Nguyen T, et al. Optic nerve diffusion changes and atrophy jointly predict visual dysfunction after optic neuritis. Neuroimage. 2009;45:679-686.

106. Song SK, Yoshino J, Le TQ, et al. Demyelination increases radial diffusivity in corpus callosum of mouse brain. Neuroimage. 2005;26: 132-140.

107. Budde MD, Xie M, Cross AH, Song SK. Axial diffusivity is the primary correlate of axonal injury in the experimental autoimmune encephalomyelitis spinal cord: a quantitative pixelwise analysis. J Neurosci. 2009;29:2805-2813.

108. Costello F, Coupland S, Hodge W, et al. Quantifying axonal loss after optic neuritis with optical coherence tomography. Ann Neurol. 2006; 59:963-969.

109. Brusa A, Jones SJ, Kapoor R, Miller DH, Plant GT. Long-term recovery and fellow eye deterioration after optic neuritis, determined by serial visual evoked potentials. J Neurol. 1999;246:776-782.

110. Brusa A, Jones SJ, Plant GT. Long-term remyelination after optic neuritis: a 2 year visual evoked potential and psychophysical serial study. Brain. 2001;124:468-479.

111. Toosy AT, Hickman SJ, Miszkiel KA, et al. Adaptive cortical plasticity in higher visual areas after acute optic neuritis. Ann Neurol. 2005; 57:622-633.

112. Korsholm K, Madsen KH, Frederiksen JL, Skimminge A, Lund TE. Recovery from optic neuritis: an ROI-based analysis of LGN and visual cortical areas. Brain. 2007;130:1244-1253. 
113. Coles A, Compston A, CAMMS223 Trial investigators. Alemtuzumab vs interferon-beta-1a in early multiple sclerosis. $N$ Eng J Med. 2008; 359:1786-1801.

114. Jeffery ND, Blakemore WF. Locomotor deficits induced by experimental spinal cord demyelination are abolished by spontaneous remyelination. Brain. 1997;120:27-37.

115. Jones SJ, Brusa A. Neurophysiological evidence for long-term repair of MS lesions: implications for axon protection. J Neurol Sci. 2003; 206:193-198.

116. Lappe-Siefke C, Goebbels S, Gravel M, et al. Disruption of Cnp1 uncouples oligodendroglial functions in axonal support and myelination. Nat Genet. 2003;33:366-374.

117. Woodruff RH, Franklin RJ. Demyelination and remyelination of the caudal cerebellar peduncle of adult rats following stereotaxic injections of lysolecithin ethidium bromide, and complement/ anti-galactocerebroside: a comparative study. Glia. 1999;25:216-228.

118. Woodruff RH, Fruttiger M, Richardson WD, Franklin RJ. Plateletderived growth factor regulates oligodendrocyte progenitor numbers in adult CNS and their response following CNS demyelination. $\mathrm{Mol}$ Cell Neurosci. 2004;25:252-262.

119. Arnett HA, Fancy SP, Alberta JA, et al. bHLH transcription factor Olig1 is required to repair demyelinated lesions in the CNS. Science. 2004;306:2111-2115.

120. Williams A, Piaton G, Aigrot MS, et al. Semaphorin 3A and 3F: key players in myelin repair in multiple sclerosis? Brain. 2007; 130:2554-2565.

121. Kotter MR, Li WW, Zhao C, Franklin RJ. Myelin impairs CNS remyelination by inhibiting oligodendrocyte precursor cell differentiation. J Neurosci. 2006;26:328-332.

122. Honmou O, Felts PA, Waxman SG, Kocsis JD. Restoration of normal conduction properties in demyelinated spinal cord axons in the adult rat by transplantation of exogenous Schwann cells. J Neurosci. 1996;16:3199-3208
123. Imaizumi T, Lankford KL, Kocsis JD. Transplantation of olfactory ensheathing cells or Schwann cells restores rapid and secure conduction across the transected spinal cord. Brain Res. 2000;854:70-78.

124. Pluchino S, Martino G. The therapeutic use of stem cells for myelin repair in autoimmune demyelinating disorders. J Neurol Sci. 2005; 233:117-119.

125. Werring DJ, Bullmore ET, Toosy AT, et al. Recovery from optic neuritis is associated with a change in the distribution of cerebral response to visual stimulation: a functional magnetic resonance imaging study. J Neurol Neurosurg Psychiatry. 2000;68:441-449.

126. Toosy AT, Werring DJ, Bullmore ET, et al. Functional magnetic resonance imaging of the cortical response to photic stimulation in humans following optic neuritis recovery. Neurosci Lett. 2002;330: 255-259.

127. Jenkins TM, Ciccarelli O, Toosy AT, et al. Dissecting structurefunction interactions in acute optic neuritis to investigate neuroplasticity. Hum Brain Mapp. 2010;31:276-286.

128. Kasten E, Wust S, Behrens-Baumann W, Sabel BA. Computer-based training for the treatment of partial blindness. Nat Med. 1998;4: 1083-1087.

129. Pluchino S, Zanotti L, Rossi B, et al. Neurosphere-derived multipotent precursors promote neuroprotection by an immunomodulatory mechanism. Nature. 2005;436:266-271.

130. Pluchino S, Gritti A, Blezer E, et al. Human neural stem cells ameliorate autoimmune encephalomyelitis in non-human primates. Ann Neurol. 2009;66:343-354.

131. Kolappan M, Connick P, Compston A, Thompson AJ, Chandran S, Miller D. Optic neuritis as a sentinel lesion to study neuroprotection and repair in a trial of autologous mesenchymal stem cells in multiple sclerosis (Abstract). Multiple Sclerosis. 2008;14:S1:284.
Eye and Brain

\section{Publish your work in this journal}

Eye and Brain is an international, peer-reviewed, open access journal focusing on clinical and experimental research in the field of neuro-ophthalmology. All aspects of patient care are addressed within the journal as well as basic research. Papers covering original research, basic science, clinical and epidemiological studies, reviews and evaluations,

\section{Dovepress}

guidelines, expert opinion and commentary, case reports and extended reports are welcome. The manuscript management system is completely online and includes a very quick and fair peer-review system, which is all easy to use. Visit http://www.dovepress.com/testimonials.php to read real quotes from published authors. 